\title{
Educational Attainment Past the Traditional Age of Completion for Two Cohorts of US Adults: Inequalities by Gender and Race/ Ethnicity
}

\author{
Alison K. Cohen ${ }^{1}$ (D) Sarah Ryan ${ }^{2} \cdot$ Louisa H. Smith ${ }^{3} \cdot$ Robert K. Ream $^{4} \cdot$ M. Maria Glymour ${ }^{5} \cdot$ Andrea Lopez $^{6}$. \\ Irene H. Yen $^{7}$
}

Accepted: 22 November 2021 / Published online: 16 December 2021

(c) The Author(s) 2021

\begin{abstract}
The vast majority of studies investigating participation in, persistence through, and consequences of postsecondary education focus on educational attainment status among the so-called traditional population of collegegoers between the ages of 18 and 24. This narrow focus leaves largely invisible the role that an expanding set of educational trajectories throughout adulthood plays in shaping social stratification. Using 35-plus and 20 years of follow-up data from the US National Longitudinal Survey of Youth (NLSY)'s 1979 and 1997 cohorts, we find that a substantial share within each cohort is attaining education well into adulthood, and that these trajectories are patterned according to key social and demographic characteristics. In both cohorts, racial/ethnic differences in educational attainment grew over time and, for those attaining the same degree, members of historically disadvantaged groups did so at an older age. Cohort differences in trajectories emerged, however, when considering the intersection of race/ethnicity and socialized gender. Through careful descriptive analysis of two generational cohorts, our study makes clear the role of educational trajectories in the process of cumulative (dis)advantage across the life course, as well as across generations.
\end{abstract}

Keywords Adulthood $\cdot$ Cumulative disadvantage $\cdot$ Disparities $\cdot$ Educational status $\cdot$ Educational trajectories $\cdot$ Nontraditional students

\section{Introduction}

Educational trajectories, entailing how much and when people attain education over time, are an often-overlooked pathway through which social stratification takes place

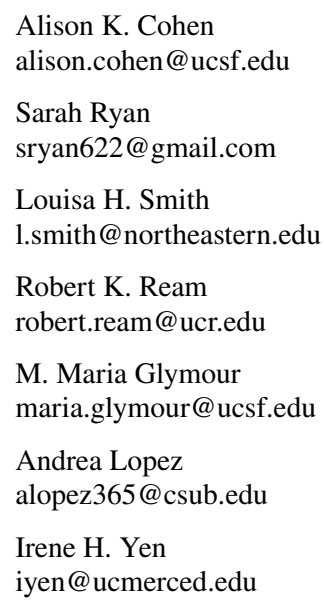

(Milesi, 2010). Although the educational career is a "transition-rich long-term trajectory within a highly structured institutional system" (Crosnoe \& Benner, 2016, p. 179), research on postsecondary education continues to focus predominantly on the six-year window following expected

1 Department of Epidemiology \& Biostatistics, School of Medicine, University of California, 550 16th Street, San Francisco, CA 94158, USA

2 Ryan Research Consulting, Madison, WI, USA

3 Roux Institute, Northeastern University, Portland, ME, USA

4 Graduate School of Education, University of California, Riverside, 2124 Sproul Hall, Riverside, CA 92521, USA

5 Department of Epidemiology \& Biostatistics, School of Medicine, University of California, San Francisco, 550 16th Street, San Francisco, CA 94158, USA

6 Department of Kinesiology, California State University Bakersfield, Bakersfield, USA

7 Department of Public Health, School of Social Sciences, Humanities \& Arts, University of California, Merced, Merced, USA 
high school completion (Grodsky et al., 2021; Haas \& Hadjar, 2020). Similarly, both policymakers and institutions have been slow to recognize and adapt to the reality that upwards of $40 \%$ of those who pursue postsecondary education do so beyond age 25 (National Center for Education Statistics [NCES] 2019), and not necessarily full-time or continuously (Bowl \& Bathmaker, 2016).

Despite all we have learned over past decades about the patterning of educational attainment according to social and demographic characteristics, there is a dearth of systematic knowledge regarding students' trajectories through higher education. Who enters, who finishes, how, and with what consequences (Haas \& Hadjar, 2020)? Importantly, how has this changed across generations? Amidst the expansion and diversification of higher education institutions that accompanied the rise of the Baby Boomer generation (Horn \& Carroll, 1996), educational pathways have become more flexible and are occupying a larger share of the life course (Weiss \& Roksa, 2016). Such flexibility has potentially opened new routes to upward social and economic mobility specifically among females and individuals from minoritized and low-income backgrounds whose participation in postsecondary education has grown during this period of expansion. In this case, we would expect to see narrowing disparities in educational attainment across key markers of social status in the United States, including gender, race and ethnicity, and socioeconomic background. It is also possible that the expansion of educational pathways over the past several generations has erected what is, in reality, only the façade of greater upward mobility for historically disadvantaged populations. These possibilities lead to very different implications for societal inequality.

There is a need to better understand the range of trajectories that socially significant subpopulations are pursuing over the life course, how this has changed across generations, and the implications for societal inequality (Ayalon et al. 2008; Crosnoe \& Benner, 2016; Elder, 1995; Grodsky et al., 2021). Thus, we explore the number of years of education and the degrees that people attain at different ages, and the extent to which these trajectories differ by select social and demographic characteristics, in the nationally representative United States (US) National Longitudinal Survey of Youth (NLSY) 1979 and 1997 cohorts. By examining variation in attainment patterns over time both within and between generational cohorts, our research underscores the need for continual investments, including research, at multiple levels of society to prevent educational trajectories from persisting as yet one more societal mechanism for the perpetuation of cumulative (dis)advantage.

\section{Social and Demographic Patterning of Educational Attainment and Trajectories Within and Across Generations}

We consider patterns in educational trajectories and attainment across two generational cohorts. The NLSY79 cohort includes individuals born between 1957 and 1964, corresponding to the final years of the Baby Boomer generation. The Pew Research Center defines Baby Boomers as those individuals born between 1946 and 1964 (Bialik \& Fry, 2019). The NLSY97 cohort includes individuals born between 1980 and 1984, corresponding to the early years of the Millennial generation, which includes those born between approximately 1981 and 1996.

In addition to being America's largest and most racially and ethnically diverse generation to date (Frey, 2018), Millennials can be distinguished from their Baby Boom (and often other generational) predecessors along numerous social, cultural, and policy fronts. For example, Millennials came of age during a period of expanding approval of issues such as the legalization of marijuana and same-sex marriage. Further, their experiences with the rapidly changing demographic composition of America stand in stark contrast to Baby Boomers, who grew up at a time when immigration was at an all-time low (Frey, 2018). Millennials have also delayed marriage and family formation later than did earlier generations (Bialik \& Fry, 2019). However, particularly relevant to this research are the educational and socioeconomic patterns that distinguish these two generations.

Individuals comprising the Millennial generation are, on average, better educated than preceding generations, corresponding to the continued expansion of participation in higher education between the NLSY79 and 97 cohorts (Weiss \& Roksa, 2016). Among Millennials, 39\% of those ages 25 to 37 had a bachelor's degree or higher in 2018, compared with just $25 \%$ of Baby Boomers when they were the same age. Millennial women have experienced particularly steep gains in educational attainment. Some $43 \%$ of Millennial women between the ages of 25 and 37 in 2018 had obtained at least a bachelor's degree compared to $24 \%$ of Baby Boomer women at the same age. Moreover, the share of Millennial women with a bachelor's degree is higher than that of men, continuing a trend observed for the first time in the preceding Generation X.

What these general patterns do not reveal, however, is whether this rising tide of educational attainment among Millennials is lifting all boats. Here, the picture is less clear. Postsecondary education attainment has also risen for all racial and ethnic young adult groups since the first Millennials were born (Frey, 2018). Yet disparities in educational attainment among White, Black, Hispanic, and Asian adults remain pervasive, with Hispanic and Black individuals 
lagging behind their White and especially East Asian counterparts (Ream et al. 2012; Bailey \& Dynarski, 2011; Weiss \& Roksa, 2016). ${ }^{1}$ Women have made substantial gains in attainment, on average, but these gains have been unevenly dispersed among women of varying racial/ethnic and socioeconomic backgrounds. Of course, differences in educational attainment within and across these two generational cohorts are perhaps unsurprising given the well-documented fact that educational opportunities and outcomes are often patterned according to demographic characteristics (e.g., race/ethnicity, social class). But status differences reveal little about the trajectories individuals are pursuing and how these trajectories vary within and across generations, and little about whether shifts in educational trajectories across generations are ameliorating or exacerbating longstanding inequities in attainment across racial/ethnic, gender, and socioeconomic markers of group membership.

\section{Describing Generational Changes in Educational Attainment Across Groups Through the Dual Lenses of Educational Trajectories and Cumulative (Dis)advantage}

Milesi (2010) defines educational trajectories as including "the type of educational experiences individuals have, the timing at which different transitions occur, and the sequence of events within educational levels" (p. 26). Over the past several decades, American students have increasingly utilized a more expansive set of postsecondary educational trajectories. Indeed, as early as 1996, Horn and Carroll observed that the so-called traditional postsecondary educational trajectory-typically defined by college entry immediately after completing high school, full-time attendance at a four-year postsecondary institution, and continuous enrollment until graduation-had become the exception, not the rule. The latest available data indicate that about $40 \%$ of US college students are over 25 years old (NCES 2019), a defining characteristic of the non-traditional college population. Researchers also consider a variety of other characteristics to define the non-traditional student population, including especially enrollment, parental, and employment status. Here, too, the data are revealing. Over half of all undergraduates attended college on a part-time basis in 2015 (Chen, Ziskin, and Torres 2020), while about 20\% of US college students are parents (Government Accountability Office, 2019) and $40 \%$ work more than $30 \mathrm{~h}$ a week (Carnevale et al., 2015).

The timing of the data collected for both waves of the National Longitudinal Survey of Youth make these data wellsuited for documenting the trend away from the historically traditional postsecondary educational trajectory and implications for societal inequality. One previous study of educational trajectories in the NLSY 1979 cohort (Milesi, 2010) reported that $48 \%$ of those who eventually attended a two-year college and $25 \%$ of those who eventually attended a four-year college did not attend college immediately after high school. In that study, adults navigating such "non-traditional" pathways through higher education also were more likely to come from historically underserved backgrounds as reflected by participants' gender, race/ethnicity, and socioeconomic position, a pattern that has been similarly observed among members of the NLSY 1997 cohort (Aughinbaugh, 2008).

On the face of it, greater participation in non-traditional trajectories is conceivably neutral in its implications for degree attainment across groups defined by socially consequential status markers such as gender, race/ethnicity, and socioeconomic position. The existence of relationships between these individual characteristics and participation in non-traditional educational trajectories does not necessarily indicate inequality in degree attainment. For this to occur, two conditions must be satisfied, according to Milesi (2010): an association between students' characteristics, background, and skills and their participation in non-traditional trajectories, and an association between students' trajectories and degree attainment. Much of the existing literature on college access and persistence indicate that these two conditions are typically satisfied, such that deviating from a traditional trajectory negatively influences students' likelihood of postsecondary degree completion. What is less clear from this literature is how this has shifted over time. As a result, we know relatively little about the extent to which educational trajectories constitute a mechanism through which disadvantages based on ascriptive characteristics may accumulate not only within but across generations.

\section{Cumulative (Dis)advantage}

11 The US Census Bureau introduced the term Hispanic in 1980, while the term Latina/o emerged into more common use in the 1990s. Most recently, younger members of this population have identified with the more gender-neutral term Latinx. Individuals within the large and diverse Hispanic/Latino population often have specific and personal reasons for their decisions about how they self-identify using one or more of these, or other, terms. In this paper, we use the terms Hispanic to reflect the term used in the Census data we cite and in the NLSY data we analyze.
Of particular relevance for examining disparities according to socially defined markers of status across time is the concept of cumulative (dis)advantage (CDA; DiPrete \& Eirich, 2006; Merton, 1988; Rank, 2009). DiPrete and Eirich (2006) describe CDA as "a general mechanism across any temporal process ... in which a favorable relative position becomes a resource that produces relative 
further gains" (p. 271) and Dannefer similarly defines $\mathrm{CDA}$ as "the systemic tendency for interindividual divergence in a given characteristic (e.g., money, health or status) with the passage of time" (Dannefer, 2018, p. S327). Students are nested in families and in schools, navigating relatively complex social lives with peers, and functioning as members of neighborhoods and communities. Research indicates that race, gender, and class dynamics are consequential in each of these domains and that these advantages or disadvantages accumulate over time such that many of the same demographic groups experiencing more disadvantage early in life also attain less education through age 25 and remain at an educational disadvantage that results in widening inequalities later in life (Alon, 2009; 2001; Raftery \& Hout, 1993).

Dannefer (2018) observes that the phenomenon of CDA is grounded in generative social dynamics that often go unrecognized such that observed patterns of increasing inequality are more readily understood than the processes that produce such patterns. Importantly, CDA is transmitted intergenerationally and can serve to perpetuate existing race and class divisions not only within but across generations (Shapiro, 2017), leading researchers to emphasize the benefit of comparative data across cohorts (Dannefer, 2018). To advance understanding of the processual role that educational trajectories may play throughout the life course, we draw on notions of cumulative (dis)advantage. We posit that the study of educational attainment can be improved by the application of theory and methods that attend to education not only as a status of school enrollment/completion but also as a potentially stratifying process inhering within the operation of temporally organized social systems such as educational and market institutions over the life course and across cohorts.

\section{Goal of Current Study}

Our study seeks to explore the breadth and fluidity of Americans' educational experiences across the life course in two national cohorts. In light of changes in the profile of the US college student population, which has occurred alongside widening economic inequality (Duncan \& Murnane, 2011), changes in racial/ethnic discrimination (Valdez \& Golash-Boza, 2017), increased opportunities for women (Collins, 2009) and a more developed prisonindustrial complex that has disproportionately ensnared men of color (Alexander, 2012), we anticipate changes in attainment trajectories across the NLSY79 and NLSY97 cohorts as we pursue the following research questions:
(1) What is the type and timing of education people attain across cohorts?

(2) Does the type/timing of education vary by sociodemographic characteristics?

We build upon a life-course conceptualization of educational trajectories (Crosnoe \& Benner, 2016; Milesi, 2010) and the concept of cumulative (dis)advantage (DiPrete \& Eirich, 2006; Elman \& O'Rand, 2004; Rank, 2009) to describe the type and timing of attainment for NLSY 1979 participants through age 40 as well as the experiences of the more recent NLSY 1997 cohort, while also considering trends across the cohorts. We explore how much education people attain over different time frames, the timing of educational attainment, and differences in educational attainment by sociodemographic characteristics. In addition to studying changes over time across cohorts, we were also interested in when inequalities emerged within a single cohort.

We coded these two complex datasets in a comparative way, using a fine-grained descriptive approach, which is especially appropriate when seeking to identify overlooked problems and generate new hypotheses and issues to further study (Loeb et al., 2017). Especially insofar as opportunities to obtain levels of education ebb and flow with changing social conditions (Müller \& Karle, 1993; Raftery \& Hout, 1993), it is worth exploring the varying opportunity structures in long-term profiles of school attendance (Roksa \& Velez, 2010; Weiss \& Roksa, 2016). To the best of our knowledge, this is the first empirical investigation comparing inequalities in later-life educational attainment across two different NLSY cohorts over a substantial portion of the life course.

\section{Methods}

\section{Data Sources}

The 1979 NLSY is a nationally representative cohort study conducted by the US Bureau of Labor Statistics that recruited 14-21 year-old US males and females in 1979 and conducted in-person and telephone interviews annually until 1994 and then biennially (for further information, see www. nlsinfo.org/content/cohorts/nlsy79). We use follow-up data through 2013. A complex multistage sampling approach randomly sampled households in the USA, screened for eligible participants, and oversampled Black youth, Hispanic youth, economically disadvantaged non-Hispanic non-Black youth, and individuals serving in the military (CHRR, 2008). The 1997 NLSY, also administered by the US Bureau of Labor Statistics, used a similar multistage sampling strategy to recruit a nationally representative cohort of adolescents ages 
12-16 in 1997; participants have been surveyed annually since (more at www.nlsinfo.org/content/cohorts/nlsy97). ${ }^{2}$

\section{Variables of Interest}

\section{Educational Attainment}

For the NLSY79 and NLSY97 cohorts, we used data through 2012 to assess continued education across the lifespan, with a focus on four ages: $25,30,35$, and 40. NLSY97 data through 2013 was used to assess continued education past 25 and 30. Each survey wave, participants reported their highest year of education attained as of that date (monthby-month data is available for NLSY97), the highest degree earned (high school/GED, associate's, bachelor's, master's, or doctoral, including professional doctorates) as of that date, and whether they were currently enrolled in school. We used month and year of birth and interview to calculate ages at which educational status was reported. Though NLSY79 educational data were less thoroughly collected, in most survey years, participants reported the month and year in which they earned degrees, allowing us to calculate their age at each degree; for degrees with no associated date, we used the halfway point since the previous interview date.

We considered participants to have continued their education past a given age if, at any time after that age, their reported number of years of education increased, they reported earning a higher degree, and/or they were enrolled in high school or higher education. We determined participants to have completed their education if they did not subsequently report being enrolled in or completing more years of formal schooling or any higher degrees; however, if there were no more data on education for an individual beyond a given age, we considered them censored and did not include them in analyses beyond that age (with the exception of calculating the average years of education at each age, for which we used a last observation carried forward method to maintain a consistent sample for year-to-year comparisons).

\section{Race/Ethnicity}

We categorized NLSY79 respondents by race/ethnicity according to the primary origin with which they identified: Black, Hispanic, Asian/Pacific Islander, and White/ other, a group which is majority White but also includes responses of "other," "American," and "Native American" (the NLSY is unable to distinguish between those with Native American/American Indian heritage and those who

\footnotetext{
${ }^{2}$ Since these data contain no personal identifiers and are publicly available, the University Institutional Review Board determined our research to be exempt from human subjects review.
}

may have misinterpreted the response choices as referring to being born in the USA, which resulted in much larger than expected proportion of the sample labeled as such (NLS 2016)). NLSY97 respondents were more carefully classified by NLSY into 6 categories, including American Indian/ Alaska Native $(n=60)$ and mixed race (non-Hispanic) $(n=83)$. For some of the racial/ethnic comparisons across the two cohorts, we used only White/other, Black, and Hispanic participants due to small sample sizes in the other groups.

\section{Other Variables}

For the NLSY79 cohort, several questions in the initial 1979 interview referred to participants at age 14, including area of residence (south/non-south, urban/rural/farm), whether parents/guardians worked for pay, and whether any household members received newspapers, magazines, or had access to a library card. Respondents also reported foreign languages spoken at home during childhood, whether they and their parents were born in the USA, and the number of years of education of each parent. In 1994, they reported whether they had attended Head Start or any other preschool. In 2012, participants were asked whether they had experienced, during childhood, living with someone with a mental illness, living with an alcoholic, and/or being physically abused.

Initial interview questions in the 1997 cohort included parental education, parental employment, region of residence, the number of places lived before age 12 , whether the mother or both parents were on the child's birth certificate, whether the child had attended Head Start, and whether s/ he had been in child care for more than 20 h/week. Parents/ guardians were also asked if children had gone through any "hard times"; examples given were living in a place without water or electricity or in a homeless shelter.

\section{Analytic Approach}

Descriptive statistics were weighted using NLSY custom longitudinal sampling weights for each cohort. Surveyweighted chi-squared tests that accounted for clustering within households (and within primary sampling units in the NLSY97 cohort) were used to compare covariate distributions across educational trajectory groups, defined by the age $(25,30,35,40)$ after which participants did not report completing more education. We graphed years of education attained by each year of age in order to examine differences in trajectories by sociodemographic characteristics. Results from these descriptive analyses are presented in Table 1 and Figs. 1, 2, and 3.

In order to better accommodate censoring, we also conducted time-to-event analyses in which we analyzed observations by age at degree completion. We emphasize 
Table 1 Weighted proportions of participants in the US National Longitudinal Survey of Youth 1979 who continued their education past age 25 , age 30 , age 35 , and age 40 , and in the US National Longitudinal Survey of Youth 1997 who continued their education past age 25 and age 30

\begin{tabular}{|c|c|c|c|c|c|c|}
\hline & $\begin{array}{l}\text { Age } 25 \\
\text { NLSY79 }\end{array}$ & $\begin{array}{l}\text { Age } 25 \\
\text { NLSY } 97\end{array}$ & $\begin{array}{l}\text { Age } 30 \\
\text { NLSY79 }\end{array}$ & $\begin{array}{l}\text { Age } 30 \\
\text { NLSY97 }\end{array}$ & $\begin{array}{l}\text { Age } 35 \\
\text { NLSY79 }\end{array}$ & $\begin{array}{l}\text { Age } 40 \\
\text { NLSY79 }\end{array}$ \\
\hline Gender & $* *$ & $* *$ & $* *$ & $* *$ & $* *$ & $* *$ \\
\hline Women & 45.2 & 47.2 & 33.0 & 19.5 & 24.5 & 16.1 \\
\hline Men & 38.1 & 36.2 & 23.9 & 13.5 & 14.2 & 8.4 \\
\hline Race/ethnicity & $* *$ & $* *$ & $* *$ & $*$ & $*$ & $* *$ \\
\hline Black & 42.8 & 43.6 & 32.1 & 19.0 & 23.2 & 16.0 \\
\hline Hispanic/Latino/a/x & 44.2 & 39.3 & 31.2 & 16.3 & 21.6 & 13.5 \\
\hline White/Other & 40.9 & 40.9 & 27.4 & 16.0 & 18.4 & 11.4 \\
\hline Asian/Pacific Islander & 62.2 & 50.8 & 46.0 & 13.5 & 31.9 & 24.1 \\
\hline Mixed Race (non-Hispanic) & & 48.0 & & 18.9 & & \\
\hline American Indian/Alaska Native & & 52.2 & & 10.6 & & \\
\hline Eventual highest degree & $* *$ & $* *$ & $* *$ & $* *$ & $* *$ & $* *$ \\
\hline No degree & 11.7 & 7.4 & 9.5 & 2.8 & 6.0 & 3.1 \\
\hline High school/equivalent & 28.3 & 32.0 & 18.3 & 13.7 & 11.8 & 6.3 \\
\hline Associate's & 63.6 & 62.0 & 47.1 & 27.9 & 34.1 & 22.2 \\
\hline Bachelor's & 52.9 & 49.6 & 34.6 & 19.5 & 23.1 & 15.3 \\
\hline Master's & 95.4 & 91.5 & 69.4 & 29.7 & 50.6 & 37.4 \\
\hline Doctoral & 94.3 & 93.9 & 49.3 & 14.2 & 29.0 & 19.4 \\
\hline Maternal education & $* *$ & $* *$ & $*$ & $* *$ & & $*$ \\
\hline$<12$ Years & 36.2 & 31.9 & 26.7 & 11.6 & 19.0 & 11.5 \\
\hline 12 years & 39.4 & 37.8 & 27.2 & 16.3 & 19.2 & 12.2 \\
\hline $12-16$ years & 54.3 & 46.9 & 33.0 & 18.4 & 20.4 & 12.6 \\
\hline$>16$ Years & 58.9 & 56.3 & 39.3 & 20.8 & 25.4 & 18.6 \\
\hline Paternal education & $* *$ & $* *$ & & $* *$ & & \\
\hline$<12$ Years & 35.6 & 29.4 & 26.9 & 11.5 & 19.3 & 12.2 \\
\hline 12 years & 39.1 & 37.6 & 27.3 & 16.0 & 18.6 & 11.0 \\
\hline $12-16$ years & 48.8 & 46.9 & 29.4 & 16.6 & 18.7 & 12.2 \\
\hline$>16$ Years & 61.0 & 56.3 & 37.4 & 20.8 & 22.8 & 15.8 \\
\hline
\end{tabular}

Note: The figure in each cell represents the proportion of individuals in that category who had data available beyond the age indicated in the column header and who continued their education beyond that age. For example, data in the first cell of the table indicates that $45.2 \%$ of females in the NLSY79 cohort who had data past age 25 continued their education past age 25

Given that there was sample attrition over time in both cohorts, there are smaller sample sizes for these analyses over time: the NLSY79 cohort had 12,034 participants who provided data at age 25, 10,289 who provided data at age $30,9,125$ who provided data at age 35 , and 8,713 who provided data at age 40 . Similarly, the NLSY97 cohort had 8,229 participants who provided data at age 25 and 5,986 who provided data at age 30 . The cohorts were relatively evenly divided by gender (at age $25,52.2 \%$ of the NLSY79 cohort and $47.5 \%$ of the NLSY97 cohort were women) and had racial/ethnic diversity (in the NLSY79 cohort, $62.6 \%$ were white, $25.8 \%$ were Black, $15.9 \%$ were Hispanic, and $1.2 \%$ were Asian; in the NLSY97 cohort, 53.4\% were white, $28.2 \%$ were Black, $22.7 \%$ were Hispanic, $1.9 \%$ were Asian, $1.0 \%$ were multiracial, and $0.8 \%$ were Native American)

Asterisks reflect results from Chi-squared tests for differences between finishers and continuers at each age, adjusted for clustering at household level (NLSY79) or complex sampling design (NLSY97). Since a single comparison may be of particular interest to a reader, we did not conduct any multiple comparisons adjustment when calculating the chi-square tests, but we only report chi-square tests that have a p-value of less than 0.01 , a more conservative cut-off that the traditional cut-point of 0.05

$* p<0.01 ; * * p<0.001$ that these analyses were not intended to isolate causal relationships, but instead to provide additional confirmation of results from our descriptive analyses. We used a multistate framework (Putter et al., 2007) in which all participants begin without a high school degree and remain in that state until they received a diploma or a GED, or were censored. We then allowed them to transition into a state defined by the completion of an Associate's degree or two years of post-high school education, at which point they were considered "at risk" to enter into the final state, attainment 

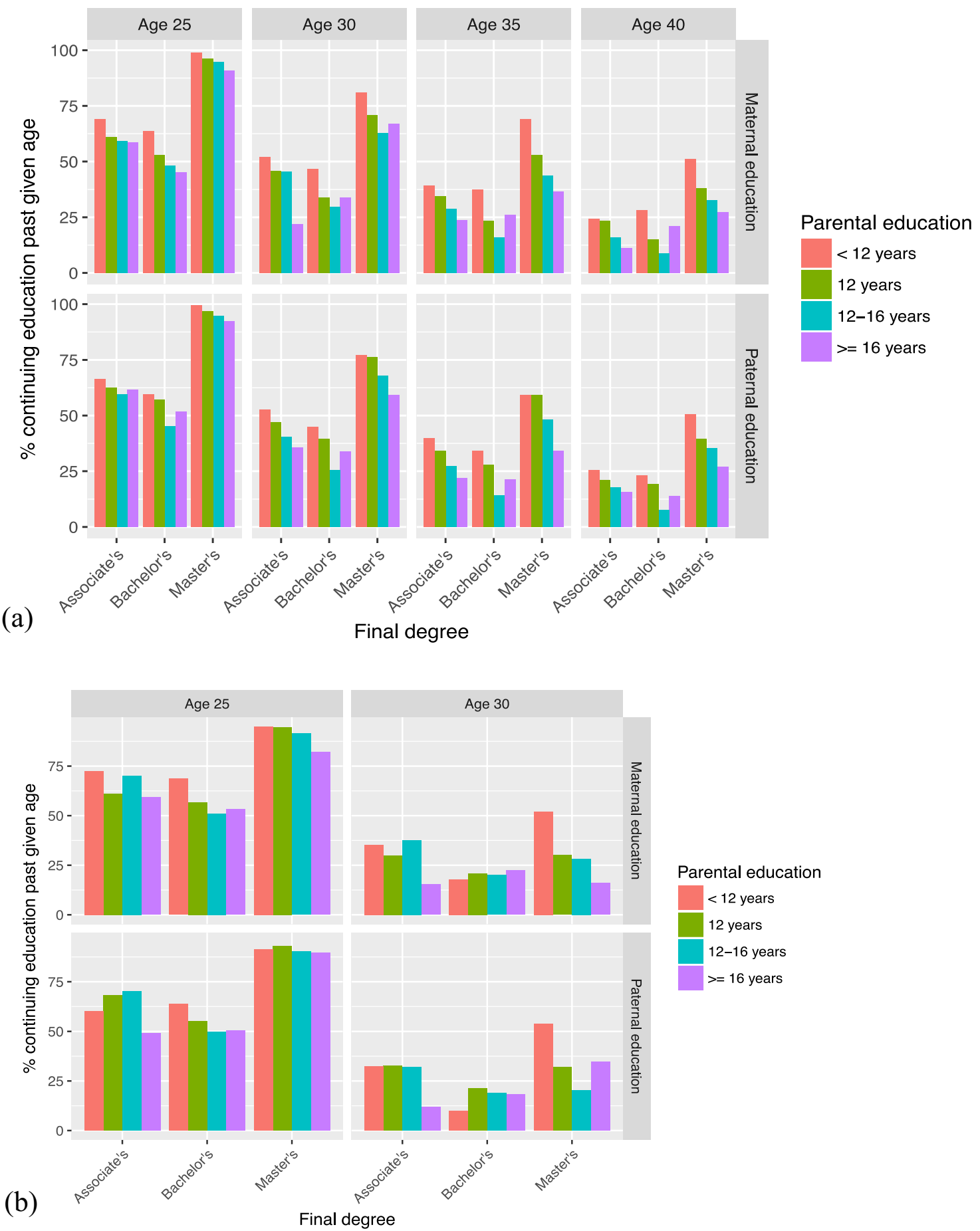

Fig. 1 Proportion of participants by final degree attained and parental education level who continued their own education past given ages in a the NLSY79 cohort (ages 25, 30, 35, 40) and b the NLSY97 cohort (ages 25, 30)

of a Bachelor's degree. This framework allowed us to analyze, on average, relative rates of degree completion across covariates using data from every NLSY79 and NLSY97 participant, regardless of length of follow-up, and without selecting only those who had completed certain degrees. We used the 'mstate' package (de Wreede
Fiocco and Putter 2011) in R version 3.4.1 and the survey functionality in Stata version 15.1 (College Station, TX) to fit Cox models that accounted for the multistate framework and complex survey design. For the Cox models, we used multiple imputation of 50 datasets to account for missing covariate information. Figures were created using 
Fig. 2 Average years of education for NLSY79 participants, stratified by race/ethnicity.

The vertical lines with bars on the top and bottom represent the $95 \% \mathrm{CI}$ for the estimated average years of education at each age
Fig. 3 Average years of education by sex and race/ethnicity (Black, Hispanic, and White/ other only), for NLSY1979 and NLSY1997 cohorts. Note: Years of education refers to the cumulative number of years of education reported by an NLSY respondent at a given age, including both those who did and did not return to education. Due to low numbers of Asians, estimates were imprecise, making comparisons difficult; they were excluded from the figure for ease of comparison between the three larger ethnic groups

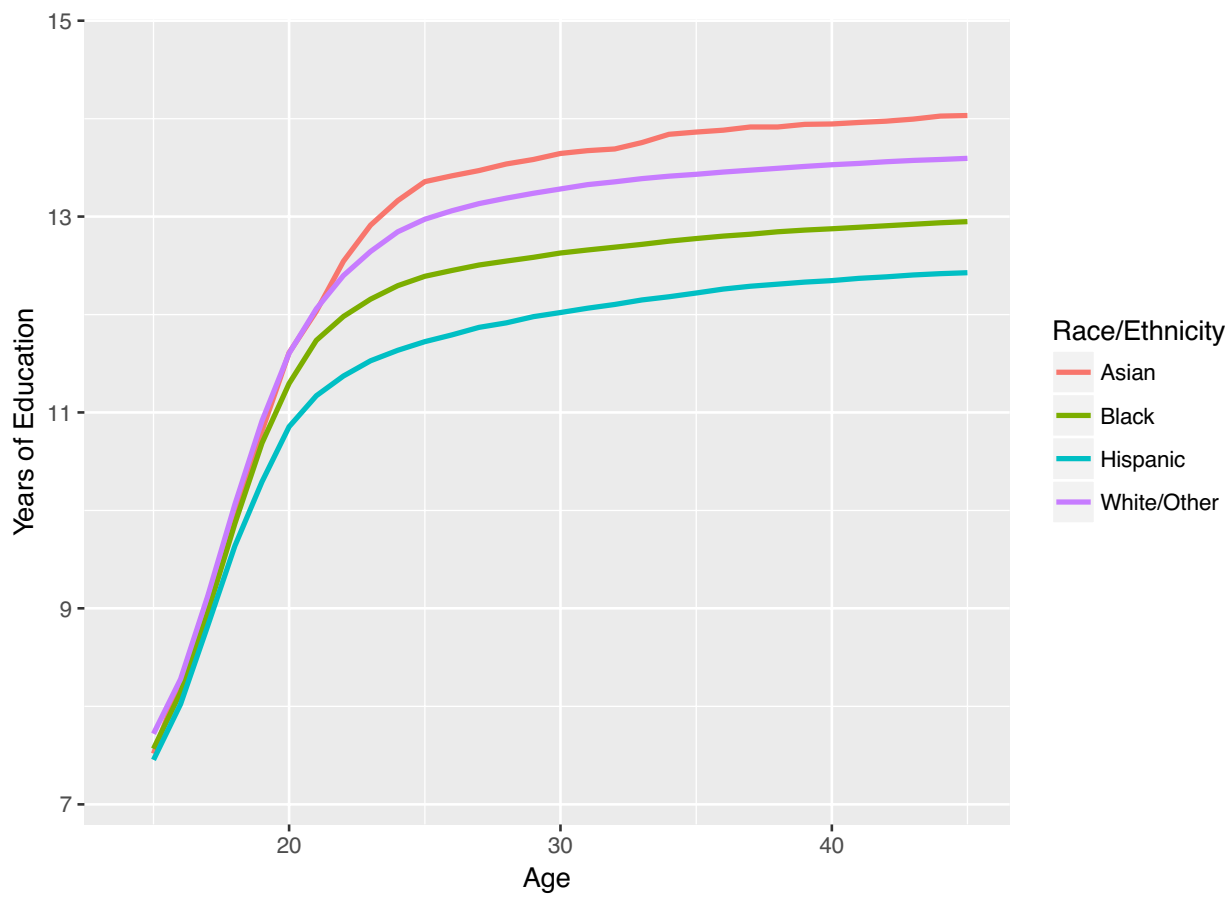

The vertical lines with bars on the top and bottom represent the $95 \%$ confidence intervals for the estimated average years of education at each age.

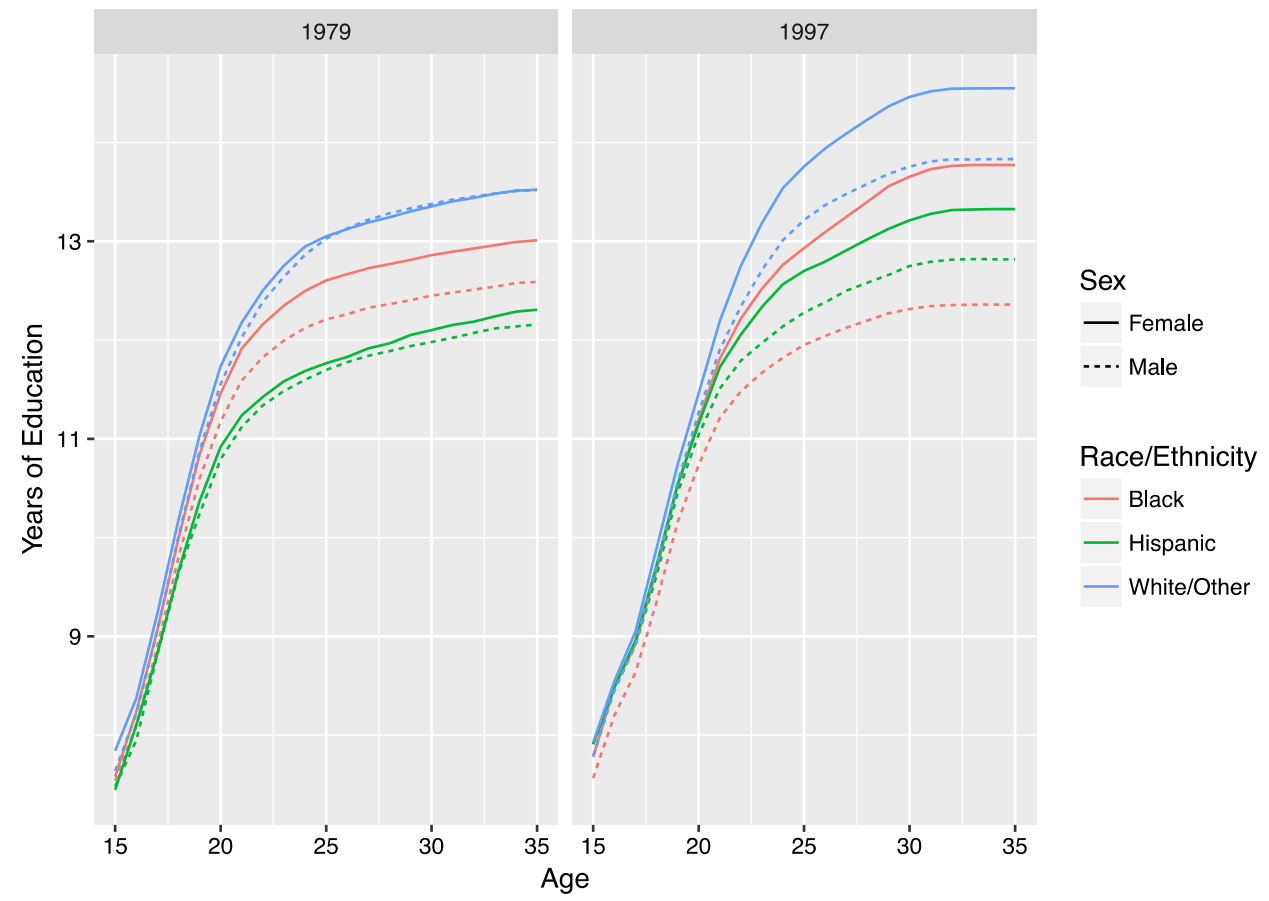

'ggplot2' (Wickham, 2009). Some of these findings are depicted in Fig. 4.

To test for differences in the education rates across cohorts, we combined the datasets and fit models using the variables for which comparisons could be made: gender, race/ethnicity, and parental education (there was little overlap in the early life variables). This required recoding the race/ethnicity variable in the NLSY97 to match the NLSY79's four categories. We accounted for householdlevel clustering. We fit multistate regression models, as 
Fig. 4 Hazard ratios (with vertical bars indicating 95\% CI) from Cox models for time to degree completion in NLSY79 and NLSY97 cohorts. Models 1 and 2 included only the covariates for which estimates are shown (i.e., sex, race/ethnicity, or parental education). Model 3 for the NLSY79 cohort also included as predictors: parental employment, health status as a child, geographic location as a child (south vs. non-south; town/city vs. farm/ranch vs. non-farm country), and childhood access to magazines, newspapers, and a library card. Model 3 for the NLSY97 cohort also included as predictors: number of places lived as a child ( $<5$ or not), the presence of both parents on the birth certificate, whether the child had gone through hard times, attended child care for $>20 \mathrm{~h} /$ week, attended Head Start, and geographic region (northeast, north central, south, west). All models use multiply imputed data for covariates, with the exception of parental variables, which were not imputed for a parent who was non-resident or unknown

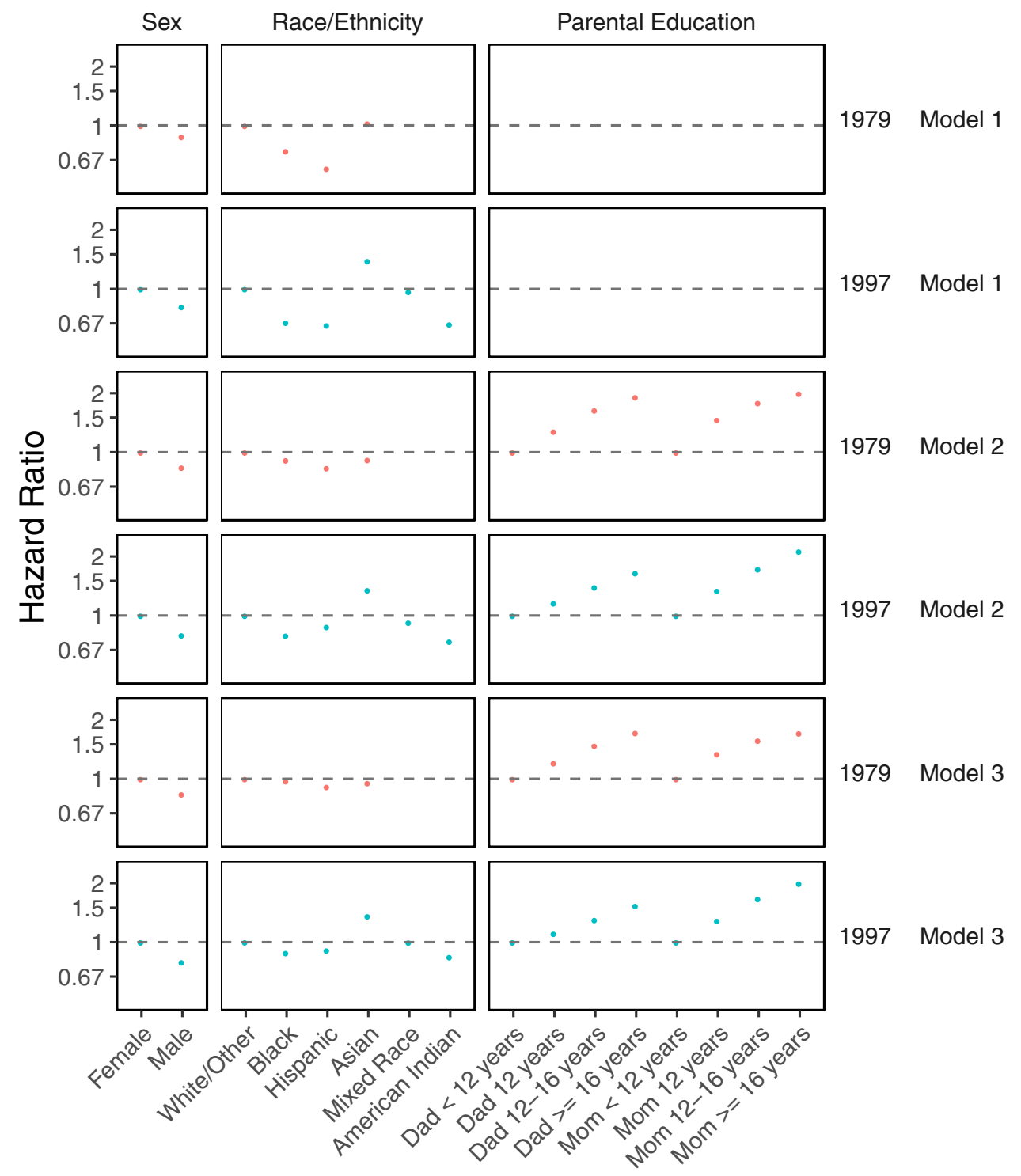

above, to the combined complete-case dataset, this time including a main cohort effect and an interaction term with cohort for all the variables in the models.

We note that we thought it was important to consider racial/ethnic inequalities without controlling for socioeconomic factors given that structural racism and other race/ ethnic-related factors can often contribute to SEP, and so SEP may mediate any disparities observed.

\section{Results}

We begin by describing trends in the timing and nature of participants' educational pursuits, both within and between the NLSY79 and NLSY97 cohorts. To provide supplemental confirmatory (or disconfirming) evidence, we then assess the statistical significance of these descriptive trends with time-to-event analyses. Our results suggest two main paths through which educational trajectories extending beyond age 25 can reinforce rather than narrow longstanding inequities according to social background. One path is indicative of cumulative advantage: people whose parents had higher education continue school longer because they are, on average, pursuing more advanced degrees. The other path is indicative of cumulative disadvantage: people from historically disadvantaged backgrounds have lower rates of degree completion across ages. When we stratify by final degree attained, those groups take longer to complete the same degree. For example, for the set of people for whom a bachelor's degree as their highest degree, those from historically disadvantaged backgrounds get a bachelor's degree later in life. These paths remain largely persistent across generations, with some key exceptions. 


\section{Descriptive Trends in the Accumulation of Education Within and Between Cohorts}

The NLSY79 and NLSY97 cohorts (Table 1) were both evenly divided by gender. A majority of participants were White, but both cohorts also included substantial numbers of Black and Hispanic participants. In both cohorts, a high school or high school equivalent degree was the most common eventual highest degree. Almost half $(42 \%)$ of our NLSY79 sample continued their education beyond age 25 , and $12 \%$ continued educational activities past age 40 (Table 1).

The extent to which the NLSY79 sample continued their education into adulthood differed by parental education and by degree attained. In the NLSY79 sample, parental education was not only a factor for overall educational attainment, but also for any given final degree attained: individuals whose parents had higher levels of education completed their own education at an earlier age, regardless of final degree. For example, among those whose highest degree was an Associate's and whose father had fewer than 12 years of education, $66 \%$ continued past age 25 , while $60 \%$ of those with an Associate's degree and whose father had 12-16 years of education continued past age 25 (Fig. 1a). Similar patterns held through age 40 , as well as for maternal education. A similar pattern was observed for NLSY97 participants. In general, NLSY97 participants whose parents had more education stayed in school for longer (Table 1), and these additional years of education were disproportionately likely to result in a more advanced degree. In contrast, NLSY97 participants whose parents had the least education were most likely to continue education past age 25 to complete the same final degree that participants with more parental education completed at a younger age. For example, among people whose parents had less than a high school education and whose final degree was a bachelors, around $69 \%$ were still getting education past age 25 , as compared to around $50 \%$ of people whose parents had $\geq 16$ years of education and whose final degree was a bachelors (Fig. 1b).

With increased age, a growing proportion of NLSY79 participants continuing their education sought Associate's degrees (Table 1). Participants whose final degree was an Associate's were more likely to continue schooling at later ages than those whose final degree was a Bachelor's. For example, $34 \%$ of people who eventually received Associate's degrees continued education past age 35, but only $23 \%$ of those whose eventual degree was a Bachelor's persisted past age 35. In general, a larger proportion of women than men continued their educational activities after age 25 (54\% vs. $46 \%$; Table 1), although differences by sex were primarily driven by the fact that Black and Hispanic/Latina women continued their education through later ages (data not shown). Similarly, in the NLSY97 cohort, a higher proportion of women than men continued education past age 25 (47\% compared to $36 \%$ ); the same was true at age 30 (20\% vs. $14 \%$ ). In this more recent cohort, however, only a slightly higher proportion of Black women continued past age $30(19 \%)$ relative to White and Hispanic/Latina women (16\% and $16 \%$, respectively).

Differences in educational attainment by race/ethnicity began to emerge when NLSY79 study participants were in their early twenties and were statistically significantly distinct by age 22 (Fig. 2). At every age after 18, Asian and White participants had more education, whether considering years of education or degrees attained, than Black and Hispanic participants (Table 1). Overall, White people whose terminal degree was an Associate's or a Bachelor's were more likely than other racial/ethnic groups to complete their education by age 25 (Fig. 1). Further, although some subset of participants from all racial and ethnic groups continued to accumulate education throughout follow-up, with each progressive age beyond 18, White participants were most likely to be completing advanced degrees while Black and Hispanic participants were most likely to continue pursuing an Associate's or Bachelor's degree. Despite the continued accumulation of education throughout follow-up, these gaps persisted. Like the 1979 cohort, in the NLSY97 cohort, White participants completed their degrees earlier than Black or Hispanic participants.

Despite overall patterns in educational trajectories according to race and sex, there were some important distinctions between the NLSY79 and NLSY97 cohorts (Fig. 3). In particular, the typical trajectories of Hispanic participants changed considerably, although the nature of these changes differed according to sex. Although Black women still attained more education than Hispanic women in both cohorts, the Black-Hispanic gap partially closed over time. And while Black men in the NLSY79 cohort attained more education than Hispanic men, the reverse was true in the NLSY97 cohort. Additionally, the White-Hispanic gap in years of education decreased slightly for both men and women between the 1979 and 1997 cohorts, although this gap remained relatively large-approximately one year of education or more.

When we tested for differences in educational attainment across the two cohorts, Asian and Hispanic participants of the 1997 cohort increased their education completion rate relative to White participants, but both Black participants and men appeared to have slowed compared to White people and women, respectively (interaction $p<0.001$ for race/ ethnicity; interaction $p=0.002$ for gender). 


\section{Testing Descriptive Trends in Attainment Disparities Over Time}

The descriptive patterns above, by which participants attained degrees at earlier and earlier ages with increasing levels of parental education, were confirmed in the timeto-event analyses. ${ }^{3}$ These differences persisted even when accounting for sex, race/ethnicity, and a variety of baseline factors that we hypothesized could influence educational attainment. Figure 4 shows the hazard ratios for each cohort from a Cox model with gender and race/ethnicity as predictors.

Models that adjusted for race/ethnicity, gender, and a number of early-life factors demonstrate the forceful influence of parental educational advantage (data available upon request). Further, our testing for differences across cohorts confirmed that the influence of parental education remained essentially unchanged over time (interaction $p=0.288$ for maternal education; interaction $p=0.544$ for paternal education). Turning to the role of race/ethnicity and sex in educational attainment disparities beyond age 25 , a direct comparison between the NLSY79 and NLSY97 cohorts similarly confirmed the inequalities at every age that were evident in the descriptive analyses. Although all race/ethnicity-gender subgroups increased educational attainment from the 1979 cohort to the 1997 cohort except Black men, subgroup educational attainment increased at different rates, leading to the perpetuation of most racial/ethnic and gender inequalities described above in both the timing and extent of educational attainment (Fig. 3). In fact, hazard ratios from the time-toevent analyses were almost identical across the two cohorts (Fig. 4). Notable is that Black-White inequalities in educational trajectories appeared to widen between the NLSY79 and NLSY97 cohorts for the ages at which both cohorts have data (up to 34 years old).

\section{Strengths and Limitations of this Research}

Our study had several strengths. First, to the best of our knowledge, this is one of the longest follow-up periods for studying educational attainment trajectories, which enabled us to more fully understand how educational attainment evolves over the lifespan. Second, we could both compare across educational transitions within a cohort over 30 years, and also across two recent US cohorts from different generations. Third, NLSY cohorts are nationally representative,

\footnotetext{
${ }^{3}$ Coefficients from complete-case and multiply imputed models were essentially identical, as were those from models in which we stratified on various factors instead of including them as predictors. We therefore present estimates from the multiply imputed models in which all covariates were included in the linear predictor.
}

increasing our study's generalizability. Fourth, we could look at trends among three major racial/ethnic groups in the USA: White people, Black people, and Hispanic people.

Our study also has limitations. First, the NLSY97 cohort seems less likely to pursue education later in adulthood compared to the NLSY79 cohort, but that may be an artifact of a shorter follow-up period. It may be that some NLSY97 participants return to school in future years. We look forward to the continued follow-up of these two cohorts to help deepen our understanding of educational trajectories across the lifespan. Second, given that the goal of this research was to describe patterns in educational trajectories beyond age 25 rather than to fully explain differences in these patterns across groups, we do not include an exhaustive set of control covariates in our analyses. As we know from prior research, a host of individual attributes are correlated with the key markers of ascribed social status that we include, especially parent education. It will be important for future analyses to further explore how attributes observed at different life stages, ranging from childhood cognitive skills to later marriage and parental status, influence educational trajectories in ways that may be correlated with parental education, race/ ethnicity, and gender (see Grodsky et al., 2021 for a recent example of such research). Third, we were limited in only being able to focus on the three major racial/ethnic groups, and not having the statistical power to further distinguish between finer classifications of race/ethnicity. We also note that there is a further level of potential inequality not explored in this paper: horizontal inequalities in the selectivity of the higher education institution attended (Mullen et al., 2003; Perna, 2000). Disparities in the eliteness of the institution could further maintain (Lucas, 2001; Raftery \& Hout, 1993 ) and/or expand inequality (Alon, 2009). We encourage the reader to keep these strengths and limitations in mind when considering the discussion of our results below.

\section{Discussion}

The vast majority of studies investigating participation in, persistence through, and consequences of postsecondary education have focused on the so-called traditional population of collegegoers between the ages of 18 and 24. This remains the case even as the non-traditional undergraduate population in the United States has expanded significantly since the mid-1970s (Chen, Ziskin and Torres 2020; Haas \& Hadjar, 2020). This narrow focus leaves largely invisible the role that an expanding set of educational trajectories throughout adulthood play in shaping social stratification. Through careful descriptive analysis, our study makes this role more visible by examining relationships between sociodemographic characteristics long shown to confer cumulative advantages across the life course, on the one hand, and 
educational trajectories, on the other hand, as well as how these relationships have changed over time.

\section{Educational Attainment and Social Stratification}

Many researchers have examined socioeconomic disparities in educational opportunities and educational attainment from kindergarten through college (Berliner, 2006; DarlingHammond, 2004; Duncan \& Murnane, 2011; Engle \& Black, 2008; Reardon \& Portilla, 2016). More recent work identifies graduate and professional education as a site of persistent stratification (Posselt \& Grodsky, 2017). We add to this literature by documenting that many continue to pursue formal educational opportunities after age 25 (when the US Census and others typically assume educational attainment to cease), and that inequalities in educational attainment widen once schooling is no longer mandatory. By examining individual educational trajectories over many decades and across generations, we find that education during adulthood is playing a more important role for social mobility and social reproduction than previously understood. Moreover, school continuation at later stages does not appear independent of social background. This is largely because Black and Hispanic people and people with low parental education take longer to attain the same degrees that White people secure much earlier in life. In fact, the results from the Cox models for parental education for both cohorts were consistent and barely changed with the inclusion of other baseline variables. Consistent with the concept of cumulative (dis)advantage, people in both the NLSY79 and NLSY97 cohorts whose parents completed more education were more likely to continue their education and to earn more advanced degrees well into adulthood, evidencing pronounced and persistent educational inheritance and socioeconomic inequalities in educational attainment.

Overall, Asian and Hispanic participants of the 1997 cohort increased their education completion rate relative to White participants, but both Black participants and men appeared to have slowed compared to White people and women, respectively. More nuanced patterns emerged when considering race and gender simultaneously. White men, who had roughly equal amounts of educational attainment as White women in the NLSY79 cohort, had much less education than White women in the NLSY97 cohort and Black women attained almost as much education as White men in the NLSY97 cohort. Black women still attained more education than Hispanic women in both cohorts, but the Black-Hispanic gap partially closed over time, while Hispanic men in the NLSY97 cohort were attaining more education than Black men, a reversal from NLSY79 trends. In both NLSY cohorts, women and people of color were more likely to continue their formal education at later ages than individuals from more historically advantaged groups.
However, among those who return to or continue education after 25, White people were more likely to complete Bachelor's degree or higher, while Black and Hispanic people were more likely to end with Associate's degrees. This is especially consequential for the Millennial (NLSY97) generation given a sharper divide in the economic status of Millennials who do and do not have a college education relative to any prior generation (Bialik \& Fry, 2019), particularly between those with a bachelor's or advanced degree versus those with less education.

\section{Implications for Future Research}

As Dannefer (2018) observes, the phenomenon of CDA finds its footing in a set of generative social dynamics that tend to go unrecognized: patterns of increasing inequality are easier to spot than the underlying processes that yield these patterns. Contributing to this opacity, an individual's structural position within a social system-although intertwined with socially consequential characteristics such as socioeconomic position, race/ethnicity, and gender-constitutes a socially generative force that can operate independently of individual characteristics. The pursuit of educational attainment over an extended timeline may serve as one underlying process of cumulative disadvantage insofar as the operation of social systems such as educational and market institutions reward normative, temporally organized schedules of attainment (O'Rand, 2002). Precocious and on-time educational attainment is typically associated with more economic opportunities, including higher-paying jobs (Angrist \& Krueger, 1991; Hout, 2012), and people can incur opportunity costs by not obtaining higher-paying jobs until later in life (DiPrete \& Eirich, 2006; Elman \& O'Rand, 2004). Other outcomes can also be affected; for example, a rich literature links higher educational attainment to better health (Cohen \& Syme, 2013), with differential returns for some marginalized groups (Vable et al., 2018). There may also be meaningful disruptions to intended educational trajectories, like marriage, parenthood, and/or other caregiving responsibilities. These considerations take on ever greater significance given that the delayed pursuit of education is common among women and members of minoritized racial/ethnic and/or socioeconomic groups, people who also encounter greater barriers to traditional educational trajectories (Grodsky \& Jones, 2007; Pérez \& McDonough, 2008). Our combined findings suggest substantial cumulative disadvantage within and across cohorts. At the same time, some of the differences we observe across generations hint at the potential for policy and program interventions within temporally organized school and labor market institutions (Elman \& O'Rand, 2004), as well as shifting social and cultural contexts, to redress these inequities. Several directions for research emerge from these findings, including the need for 
research to assess how the type, timing, and sequence of educational attainment perpetuates inequities within and across generational cohorts, as well as research to understand the structural forces that may lead these educational inequities to manifest.

One research direction is toward policy analysis that uses a long-range view to shed light on how broad policy reforms may condition educational trajectories in ways that are consequential for particular groups. Importantly, the operation of inherent systemic dynamics that produce tendencies toward CDA does not exclude the possibility that factors outside the system will influence CDA, in either direction (Dannefer, 2018). Indeed, we observe that the educational trajectories of White women further diverged from their Hispanic and Black peers between the NLSY79 and 97 cohorts during a period which, despite increasing racial and ethnic diversity, White women were among the greatest beneficiaries of affirmative action (Hall, 2015). Meanwhile, Black men are the only group for which we observe a waning trajectory and decrease in attainment over a time period that coincides with the mass incarceration of this population. While, importantly, we cannot ascertain the causal order of these phenomena given the descriptive nature of this research, our results illustrate the value of rich descriptive analysis for lifting out trends that might otherwise go unnoticed, as well as the value of comparing these trends over time. Especially insofar as opportunities to obtain levels of education ebb and flow with changing social conditions (Müller \& Karle, 1993; Raftery \& Hout, 1993), it is crucial to account for the exogenous forces that disrupt long-term profiles of school attendance within and across cohorts (Roksa \& Velez, 2010; Weiss \& Roksa, 2016). Intergenerational analyses are arguably key given that such interventions, even when successful in modifying outcomes for one generation, may do little to disrupt the underlying systemic tendencies that generate CDA (Dannefer, 2018). We encourage researchers to continue conducting detailed intersectional analyses to more fully understand patterns by race and sex, and to explore not only which interventions may be particularly beneficial for those who are historically disadvantaged but also the extent to which such interventions prove durable across generations.

Another direction for research is toward a more developed understanding of the structural forces that lead to the accumulation of disadvantage across the life course, and across lifetimes. Haas and Hadjar (2019) emphasize conceptual parallels between life-course sociology (Crosnoe \& Benner, 2016; Settersten \& Mayer, 1997) and research on trajectories in higher education (Milesi, 2010) and the potential value in their combination for understanding how variations in educational attainment trajectories are shaped by micro-, meso-, and macro-level processes. Identifiable mechanisms and processes embedded in everyday social life across system levels, from micro to macro, give rise to cumulative (dis)advantage (Dannefer, 1987, 2003; Elias \& Feagin, 2016; Pallas \& Jennings, 2009). In particular, microlevel dynamics constitute the most fundamental level at which CDE processes operate given their significance in shaping an individual's characteristics, identity, and sense of agency in the world (Dannefer, 2018). Such processes contribute to organizational narratives that condition access to resources and opportunities as individuals move through educational institutions across time (Holstein \& Gubrium, 2000). ${ }^{4}$

Finally, we point to a need for research that interrogates the degree to which the effects of programmatic or policy interventions in childhood endure and for whom across the midlife years, particularly given the lack of research focus on this period relative to early-life effects (Dannefer, 2018). For instance, high-quality early childhood education is associated with increased and "on-time" educational attainment (Deming, 2009; Heckman et al., 2010); our study similarly found that a higher proportion of those who participated in Head Start attained education at all ages than those who did not. Less clear is the extent to which such effects are contingent upon the nature of resource allocation across the years of midlife according to individuals' structural positions (Dannefer, 2018).

Research in each of these directions must necessarily draw on a range of theoretical and disciplinary perspectives. Although a wide range of research addresses educational inequality at key junctions along the pathway into and through undergraduate education (Brint \& Karabel, 1989; Coleman et al., 1966; Contreras, 2011; Gamoran, 1987), we argue that our findings on late-stage educational attainment are not sufficiently explained by any single theory to date. Some components of some theories are useful, including classical educational transitions (Mare, 1980), the neo-classical response to purported late state egalitarianism (Alon, 2009; Lucas, 2001; Raftery \& Hout, 1993), and perhaps especially the cumulative (dis)advantage perspective on educational inheritance and status attainment within temporally organized schools and market institutions (DiPrete \& Eirich, 2006; Elman \& O'Rand, 2004; Merton, 1988). Recent research (Grodsky et al., 2021) provides an example of the kind of scholarship needed to advance theory on educational trajectories across the life course. These authors build from CDA to propose a theory of "staged advantage," based on the premise that the intersection of life-course events and educational trajectories as a cohort ages may produce varied

\footnotetext{
${ }^{4}$ For example, labeling and altercasting, whereby one student is deemed hopeless while another is acclaimed as evidencing boundless potential in conversations among educators, often combine with organizational dynamics to guarantee stratification that is in turn augmented through processes at various other levels of the system over time (Dannefer 2018).
} 
patterns of relative advantage and disadvantage at different stages.

\section{Conclusion}

In both the NLSY79 and 97 cohorts, which in turn correspond to the Baby Boomer and Millennial generations, racial/ethnic inequalities in educational attainment grew from adolescence into adulthood, and socioeconomic inequalities also were more pronounced for more advanced degrees and at later ages. While many institutions of higher education remain focused on the stereotypical student of decades past who is straight out of high school, our detailed descriptive analyses suggest that educational trajectories well into adulthood are serving as yet another overlooked process through which advantages and disadvantages differentially accumulate in timeworn patterns across groups.

Funding This work was supported by the National Institutes of Health [Grant Number R01AG056360] and UCSF's Health Disparities Working Group [Seed Grant].

Data Availability The analyses were conducted using data that are publicly available.

Code Availability Custom code may be shared upon reasonable request.

\section{Declarations}

Conflict of interest The authors have no conflicts of interest to disclose.

Open Access This article is licensed under a Creative Commons Attribution 4.0 International License, which permits use, sharing, adaptation, distribution and reproduction in any medium or format, as long as you give appropriate credit to the original author(s) and the source, provide a link to the Creative Commons licence, and indicate if changes were made. The images or other third party material in this article are included in the article's Creative Commons licence, unless indicated otherwise in a credit line to the material. If material is not included in the article's Creative Commons licence and your intended use is not permitted by statutory regulation or exceeds the permitted use, you will need to obtain permission directly from the copyright holder. To view a copy of this licence, visit http://creativecommons.org/licenses/by/4.0/.

\section{References}

Alexander, M. (2012). The new Jim Crow: Mass incarceration in the age of colorblindness. The New Press.

Alon, S. (2009). The evolution of class inequality in higher education. American Sociological Review, 74, 731-755.

Angrist, J. D., \& Krueger, A. B. (1991). Does compulsory school attendance affect schooling and earnings? The Quarterly Journal of Economics, 106(4), 979-1014.
Aughinbaugh, A. (2008). Who goes to college-evidence from the NLSY97. Monthly Laboratory Review, 133, 31.

Ayalon, H., Grodsky, E., Gamoran, A., \& Yogev, A. (2008). Diversification and inequality in higher education: A comparison of Israel and the United States. Sociology of Education, 81(3), 211-241.

Bailey, M. J., \& Dynarski, S. M. (2011). Gains and gaps: Changing inequality in US college entry and completion. National Bureau of Economic Research., 5, 19-88.

Berliner, D. (2006). Our impoverished view of educational research. Teachers College Record, 108(6), 949-995.

Bialik, K., \& Fry, R. (2019). Millennial life: How young adulthood today compares with prior generations. Pew Research Center.

Bowl, M., \& Bathmaker, A. (2016). 'Non-traditional' students and diversity in higher education. In J. E. Cote \& A. Furlong (Eds.), Routledge Handbook of the Sociology of Higher Education (pp. 142-152). Routledge.

Brint, S., \& Karabel, J. (1989). The diverted dream: Community colleges and the promise of educational opportunity in America, 1900-1985. Oxford University Press on Demand.

Carnevale, A. P., Smith, N., Melton, M., \& Price, E. W. (2015). Learning while earning: The new normal. Georgetown University Center on Education and the Workforce.

Chen, J., Ziskin, M. B., \& Torries, V. (2020). An analysis of factors affecting dropout risks of notraditional students: Evidence from U.S. 4-year commuter institutions. International Journal of Educational Reform, 29(1), 38-59.

CHRR. (2008). NLSY79 user's guide. Center for Human Resource Research, Ohio State University.

Cohen, A. K., \& Syme, S. L. (2013). Education: A missed opportunity for public health intervention. American Journal of Public Health, 103(6), 997-1001.

Coleman, J., Campbell, E., Hobson, C., McPartland, J., Mood, A., Weinfeld, F., \& York, R. (1966). Equality of educational opportunity (Report No. OE-38001). Retrieved from the ERIC website: https://files.eric.ed.gov/fulltext/ED012275.pdf

Collins, G. (2009). When everything changed: The amazing journey of American women from 1960 to the present. Little Brown and Company.

Contreras, F. (2011). Strengthening the bridge to higher education for academically promising underrepresented students. Journal of Advanced Academics, 22(3), 500-526.

Crosnoe, R., \& Benner, A. D. (2016). Educational pathways. In M. J. Shanahan, J. T. Mortimer, \& M. K. Johnson (Eds.), Handbook of the life course. Springer International Publishing.

Dannefer, D. (1987). Aging as intracohort differentiation: Accentuation, the Matthew effect, and the life course. Sociological Forum, 2, 211-236.

Dannefer, D. (2018). Systemic and reflexive: Foundations of cumulative dis/advantage and life-course processes. Journals of Gerontology, 75(6), 1249-1263.

Darling-Hammond, L. (2004). The color line in American education: Race, resources, and student achievement. Du Bois Review: Social Science Research on Race, 1(02), 213-246.

Deming, D. (2009). Early childhood intervention and life-cycle skill development: Evidence from Head Start. American Economic Journal: Applied Economics, 1(3), 111-134.

de Wreede, L. C., Fiocco, M., \& Putter, H. (2011). mstate: An R package for the analysis of competing risks and multi-state models. Journal of Statistical Software, 38(7), 1-30.

DiPrete, T. A., \& Eirich, G. M. (2006). Cumulative advantage as a mechanism for inequality: A review of theoretical and empirical developments. Annual Review of Sociology, 32(1), 271-297.

Duncan, G. J., \& Murnane, R. J. (Eds.). (2011). Whither opportunity?: Rising inequality, schools, and children's life chances. Russell Sage Foundation. 
Elder, G. H. (1995). The life course paradigm: Social change and individual development. In P. Moen, G. H. Elder, \& K. Luescher (Eds.), Examining lives in context: Perspectives on the ecology of human development (pp. 101-140). American Psychological Association.

Elias, S., \& Feagin, J. R. (2016). Racial theories in social science: A systemic racism critique. Routledge.

Elman, C., \& O'Rand, A. M. (2004). The race is to the swift: Socioeconomic origins, adult education, and wage attainment. American Journal of Sociology, 110(1), 123-160.

Engle, P. L., \& Black, M. M. (2008). The effect of poverty on child development and educational outcomes. Annals of the New York Academy of Sciences, 1136(1), 243-256.

Frey, W. (2018). The millennial generation: A demographic bridge to America's future. Brookings Institution.

Gamoran, A. (1987). The stratification of high school learning opportunities. Sociology of Education, 60, 135-155.

Government Accountability Office. (2019). Higher Education: More Information Could Help Student Parents Access Additional Federal Aid. Report to Congressional Requestors. GAO 19-522. Author.

Grodsky, E., \& Jones, M. T. (2007). Real and imagined barriers to college entry: Perceptions of cost. Social Science Research, 36(2), $745-766$.

Grodsky, E., Doren, C., Hung, K., Muller, C., \& Warren, J. R. (2021). Continuing education and stratification at midlife. Sociology of Education, 94(4), 341-360.

Hall, P. D. (2015). White fragility and affirmative action. The Journal of Race \& Policy, 12(2), 7-21.

Haas, C., \& Hadjar, A. (2020). Students' trajectories through higher education: A review of quantitative research. Higher Education, 79(6), 1009-1118.

Heckman, J. J., Moon, S. H., Pinto, R., Savelyev, P. A., \& Yavitz, A. (2010). The rate of return to the HighScope Perry Preschool Program. Journal of Public Economics, 94(1-2), 114-128.

Holstein, J. A., \& Gubrium, J. F. (2000). Constructing the life course. Rowman and Littlefield.

Horn, L. J., \& Carroll, C. D. (1996). Nontraditional Undergraduates: Trends in Enrollment from 1986 to 1992 and Persistence and Attainment among 1989-90 Beginning Postsecondary Students. Postsecondary Education Descriptive Analysis Reports. Statistical Analysis Report. US Government Printing Office.

Hout, M. (2012). Social and Economic Returns to College Education in the United States. Annual Review of Sociology, 38(1), 379-400.

Loeb, S., Dynarski, S., McFarland, D., Morris, P., Reardon, S., \& Reber, S. (2017). Descriptive analysis in education: A guide for researchers. (NCEE 2017-4023). U.S. Department of Education, Institute of Education Sciences, National Center for Education Evaluation and Regional Assistance.

Lucas, S. R. (2001). Effectively maintained inequality: Education transitions, track mobility, and social background effects. American Journal of Sociology, 106(6), 1642-1690.

Mare, R. D. (1980). Social background and school continuation decisions. Journal of the American Statistical Association, 75(370), 295-305.

Merton, R. K. (1988). The matthew effect in science, II: Cumulative advantage and the symbolism of intellectual property. Isis, 79(4), $606-623$.

Milesi, C. (2010). Do all roads lead to Rome? Effect of educational trajectories on educational transitions. Research in Social Stratification and Mobility, 28(1), 23-44.

Mullen, A. L., Goyette, K. A., \& Soares, J. A. (2003). Who goes to graduate school? Social and academic correlates of educational continuation after college. Sociology of Education, 44, 143-169.
Müller, W., \& Karle, W. (1993). Social selection in educational systems in Europe. European Sociological Review, 9(1), 1-23.

National Center for Education Statistics. 2019. Digest of education statistics: 2019. Institute of Education Sciences

NLS (2016). https://www.nlsinfo.org/content/cohorts/nlsy79/topicalguide/household/race-ethnicity-immigration-data

O'Rand, A. M. (2002). Cumulative advantage theory in life course research. Annual Review of Gerontology and Geriatrics, 22(1), $14-30$.

Pallas, A. M., \& Jennings, J. L. (2009). Cumulative knowledge about cumulative advantage. Swiss Journal of Sociology, 35, 211-229.

Pérez, P. A., \& McDonough, P. M. (2008). Understanding Latina and Latino college choice: A social capital and chain migration analysis. Journal of Hispanic Higher Education, 7(3), 249-265.

Perna, L. W. (2000). Differences in the decision to attend college among African Americans, Hispanics, and Whites. The Journal of Higher Education, 71(2), 117-141.

Posselt, J. R., \& Grodsky, E. (2017). Graduate education and social stratification. Annual Review of Sociology, 43, 353-378.

Putter, H., Fiocco, M., \& Geskus, R. B. (2007). Tutorial in biostatistics: Competing risks and multi-state models. Statistics in Medicine, 26(11), 2389-2430.

Raftery, A. E., \& Hout, M. (1993). Maximally maintained inequality: Expansion, reform, and opportunity in irish education, 1921-75. Sociology of Education, 66(1), 41-62.

Rank, M. R. (2009). Measuring the economic racial divide across the course of American lives. Race and Social Problems, 1(2), 57-66.

Ream, R. K., Ryan, S. M., \& Espinoza, J. A. (2012). Reframing the ecology of opportunity andachievement gaps: Why "no excuses" reforms have failed to narrow student group differences in educationaloutcomes. Narrowing the achievement gap: Perspectives and strategies for challenging times (pp. 35-56).

Reardon, S. F., \& Portilla, X. A. (2016). Recent trends in income, racial, and ethnic school readiness gaps at kindergarten entry. AERA Open, 2(3), 2332858416657343.

Roksa, J., \& Velez, M. (2010). When studying schooling is not enough: Incorporating employment in models of educational transitions. Research in Social Stratification and Mobility, 28(1), 5-21.

Settersten, R. A., Jr., \& Mayer, K. U. (1997). The measurement of age, age structuring, and the life course. Annual Review of Sociology, 23(1), 233-261.

Shapiro, T. (2017). Toxic inequality: How America's wealth gap destroys mobility, deepens the racial divide, and threatens our future. Basic.

Vable, A. M., Cohen, A. K., Leonard, S. A., Glymour, M. M., Duarte, C., \& dP., \& Yen, I. H. (2018). Do the health benefits of education vary by sociodemographic subgroup? Differential returns to education and implications for health inequities. Annals of Epidemiology, 28(11), 759-766.

Valdez, Z., \& Golash-Boza, T. (2017). US racial and ethnic relations in the twenty-first century. Ethnic and Racial Studies, 40(13), 2181-2209.

Weiss, F., \& Roksa, J. (2016). New dimensions of educational inequality: Changing patterns of combining college and work in the U.S. over time. Research in Social Stratification and Mobility, $44,44-53$.

Wickham, H. (2009). ggplot2: Elegant graphics for data analysis. Springer.

Publisher's Note Springer Nature remains neutral with regard to jurisdictional claims in published maps and institutional affiliations. 